\title{
The Properties of Nerve Cell Precursors in Hydra
}

\author{
Thomas Holstein and ChaRles N. David \\ Department of Zoology, University of Munich, Luisenstrasse 14, D-8000 Munich 2, West Germany \\ Received February 15, 1985; accepted in revised form November 14, 1985
}

\begin{abstract}
Two signals, the head activator and an injury stimulus, control differentiation of nerve cells from uncommitted stem cells in hydra [Th. Holstein, H. C. Schaller, and C. N. David, (1986) Dev. Biol. 115, 9-17]. The time of action of these signals in the precursor cell cycle was determined. Methanol extracts of hydra containing $10^{-13} M$ head activator cause nerve cell commitment in $\mathrm{S}$ phase of the precursor cell cycle. Committed precursors complete the cell cycle, divide, and arrest in G1. Injury relieves the G1 block and precursors differentiate nerve cells. Under these conditions the time from commitment to nerve differentiation is $12 \mathrm{hr}$, the time from the end of $S$ phase to nerve differentiation is $9 \mathrm{hr}$, and the time from the G1 block to nerve differentiation is $4 \mathrm{hr}$. Committed precursors blocked in G1 are unstable, decaying with a half-life of $12 \mathrm{hr}$ if not stimulated to differentiate by an injury stimulus. c) 1986 Academic Press. Inc.
\end{abstract}

\section{INTRODUCTION}

Interstitial stem cells in hydra give rise continuously to differentiated nerve cells and nematocytes (David and Gierer, 1974; Bode and David, 1978). The stem cells are multipotent (David and Murphy, 1977) and there is extensive evidence that morphogenetic signals control the choice of differentiation pathway (Venugopal and David, 1981a; Yaross and Bode, 1978b). Evidence in the preceding paper demonstrates that commitment to the nerve pathway is controlled by the head activator, a neuropeptide present in hydra tissue (Holstein et al., 1986). Thus, the head activator controls the partitioning of stem cells between the nerve and nematocyte pathway. Head activator alone, however, does not stimulate nerve cell differentiation in normal tissue since committed nerve precursors require a second signal to complete differentiation. The nature of this second signal is presently unknown. However, it appears to arise normally in the course of bud initiation and it can be mimicked by injury. The signal is long-lived and appears to remain localized in tissue at the site of bud formation or injury.

The goal of the present investigation was to localize the time of action of head activator and the injury signal in the cell cycle of the nerve precursor. The results indicate that commitment occurs in $\mathrm{S}$ phase. Committed precursors then complete the cell cycle, divide, and arrest in G1. Injury stimulates arrested G1 cells to complete nerve differentiation. Thus nerve differentiation is controlled at two points in the cell cycle.

\section{MATERIALS AND METHODS}

Culture conditions. Hydra attenuata were cultured at

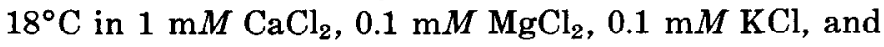

$1 \mathrm{mM} \mathrm{NaHCO}$, adjusted to $\mathrm{pH} 7.8$, as described by Holstein et al. (1986). Budless hydra were used in all experiments. Animals were selected from the culture $22 \mathrm{hr}$ after the last feeding. Such animals contain about 9000 epithelial cells and about 40,000 total cells.

Identification of cell types by maceration. The identification and quantitation of cell types were performed in macerated preparations (David, 1973) as described by Holstein et al. (1986). Counts were done with a Zeiss phase-contrast microscope using Plan-Neofluar objectives $(25 / 0.8,40 / 0.75,63 / 0.9)$. For the experiments reported here from 100 to 300 nerve cells and 700 to 3000 epithelial cells wre counted in a given sample.

Labeling with $\left[{ }^{s} H\right]$ thymidine and autoradiography. Hydra were labeled with $\left[\right.$ methyl $\left.-{ }^{3} \mathrm{H}\right]$ thymidine and autoradiographed as described by Holstein et al. (1986).

Assays for committed neme precursors. Committed nerve precursors were assayed in explants or in whole hydra which were injured as described in Holstein et al. (1986). Fifteen explanted pieces (containing about 15001600 epithelial cells) per sample were incubated in $10 \mathrm{ml}$ hydra medium; whole hydra, injured with three transverse cuts in the body column, were incubated at a density of 10 animals $/ 10 \mathrm{ml}$ of hydra medium.

Preparation of methanol extract. Methanol extract containing head activator was prepared from hydra tissue as described by Holstein et al. (1986). The concentration of head activator in the extract was determined by radioimmunoassay (Bodenmüller and Zachmann, 1983). Methanol extract was used to stimulate nerve cell commitment in all the experiments reported here. Head activator is the active component causing nerve cell commitment in such extracts (Holstein et al., 1986). The concentration of methanol extract used in individual experiments is given in terms of its head activator content. 
The methanol extract of 1 budless hydra/ml contains $2.0 \times 10^{-13} M$ head activator (Holstein et al., 1986).

Microfluorometric determination of nuclear DNA content. Macerated preparations of hydra cells on gelatincoated slides were washed for $10 \mathrm{~min}$ in PBS buffer $(0.15$ $M \mathrm{NaCl}, 0.01 M$ potassium phosphate buffer, $\mathrm{pH} 7.4)$ and stained for $8 \mathrm{hr}$ with the DNA-specific fluorochrome DAPI $(0.5 \mu \mathrm{g} / \mathrm{ml})$ (Leeman and Ruch, 1982) in McIlvaine's buffer ( $\mathrm{pH}$ 7.0) (Coleman and Maguire, 1982). The slides were washed briefly in PBS, covered with a drop of PBS-glycerin (1:3), and kept in the dark until measured.

The fluorescence of nuclei was measured with a Leitz Dialux microscope fitted with a Leitz epifluorescence attachment using filter block $\mathrm{A}$. The light of the $50-\mathrm{W}$ mercury lamp was reduced two times with a neutral density filter in order to reduce the bleaching of the DAPI fluorescence. Measurements were made with a 40/0.70 NPL-Fluotar objective. Fluorescence intensity was measured with a Leitz MPV microscope photometer equipped with a variable diaphragm which was adjusted to the size of large interstitial cell nuclei. The photometer was connected to a Kontron PSI 80 microcomputer, which performed all data collection and handling.

\section{RESULTS}

Commitment of nerve cell precursors by head activator occurs in $S$ phase. Nerve cell differentiation in hydra requires two signals: head activator to induce nerve cell commitment and a second "injury" signal to cause differentiation of committed nerve precursors (Holstein et al., 1986). In order to determine the phase in the cell cycle during which these signals work, we investigated the kinetics of nerve cell differentiation following treatment of hydra with a methanol extract containing head activator. Two different experimental protocols were used. In the first protocol animals were injured prior to treatment with methanol extract. Under these conditions, committed precursors complete differentiation to nerve cells (Holstein et al., 1985). Thus it is possible to estimate the time of commitment with respect to nerve differentiation. In the second protocol animals were treated with methanol extract to induce committed nerve precursors. Under these conditions committed precursors accumulate (Holstein et al., 1986; see also Figs. 3 and 4). Differentiation of these precursors was then induced by a subsequent injury stimulus.

To determine the time of action of methanol extract, we measured the time lag between the onset of treatment and the first appearance of newly differentiated nerve cells. Hydra were incubated for varying periods of time in methanol extract containing $10^{13} M$ head activator. Prior to treatment the animals were injured so that committed nerve cells would complete differentiation without delay (Holstein et al., 1986). Figure 1 shows that during the first $12 \mathrm{hr}$ of treatment the Nv/Epi ratio increased slightly from 0.11 to $\sim 0.12$. Beginning at $12 \mathrm{hr}$ the Nv/Epi ratio increased sharply to 0.20 in treated but not in control animals. The timing of this increase indicates that head activator causes commitment of nerve precursors at a point $12 \mathrm{hr}$ before differentiation. Based on the cell cycle of nerve precursors (Venugopal and David, 1981b), this places commitment in the S phase.

This conclusion depends, however, on the assumption that there is no lag between methanol extract treatment and the onset of nerve cell commitment. The results in Fig. 8, which show that nerve cell commitment begins immediately upon treatment with methanol extract, clearly confirm this assumption.

To localize the time of commitment more precisely with respect to the S/G2 boundary we used the "hydroxyurea-escape" procedure (Fujisawa and David, 1982). Hydra were injured and then incubated with methanol extract to induce nerve cell differentiation. At varying times thereafter hydroxyurea $(0.01 M)$ was added to block progression of S-phase cells through the cycle (under these conditions inhibition of DNA synthesis is $98 \%$ effective in $20 \mathrm{~min}$ ); cells in G2 are unaffected by this procedure and continue to progress through the cell cycle. Figure 2 indicates that nerve precursors become resistant to hydroxyurea treatment (i.e., progress from S phase into G2) beginning about $3 \mathrm{hr}$ after the onset of methanol extract treatment. The number of these precursors increases as the interval be-

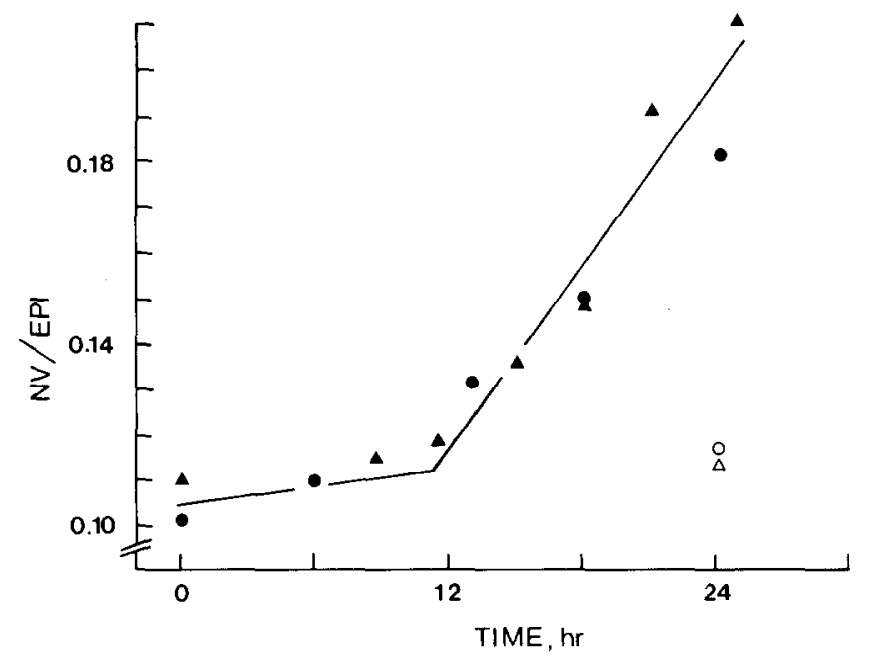

FIG. 1. Increase in ratio of Nv/Epi in whole hydra which were injured and then treated with methanol extract containing $10^{-13} M$ head activator. At the times indicated pieces were macerated and scored for nerve cells $(\mathrm{Nv})$ and epithelial cells (Epi). Different symbols represent independent experiments. Treated hydra $(\bullet, \wedge)$; untreated (but injured) control hydra $(O, \Delta)$. 


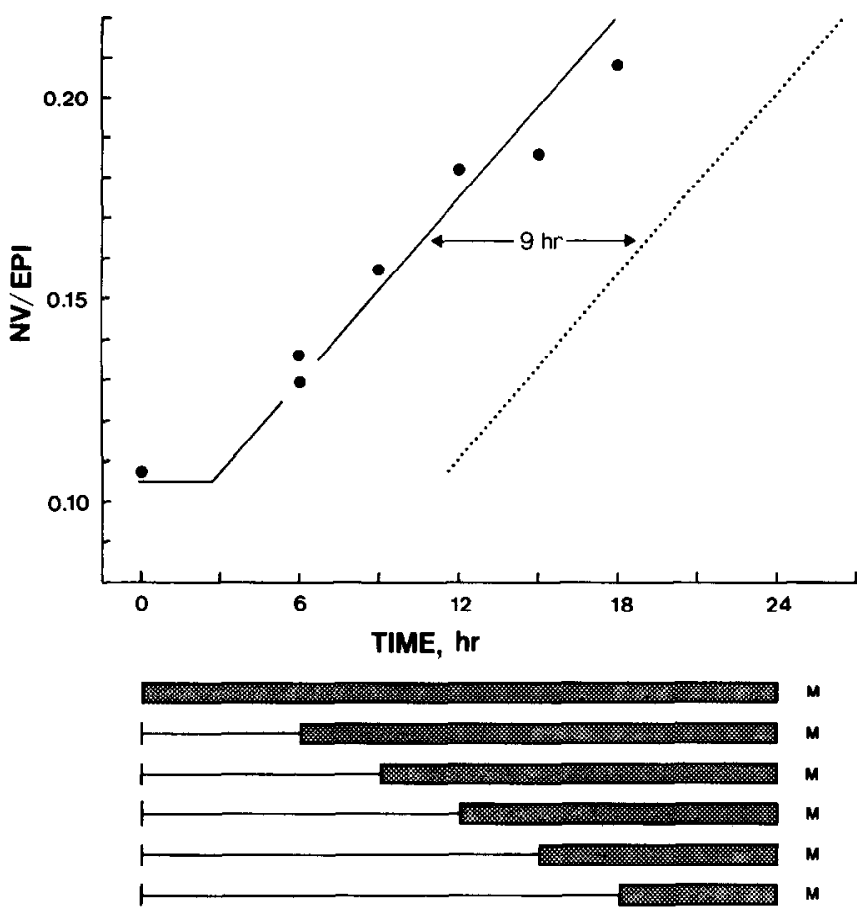

Fig. 2. Determination of the S/G2 boundary of nerve precursors by the "hydroxyurea-escape" procedure (see text). Hydra were injured and treated with methanol extract containing $10^{-13} M$ head activator. At the times shown, $0.01 M$ hydroxyurea was added to the dishes (see bars). The samples were macerated (M) at $24 \mathrm{hr}$ and scored for nerve cells $(\mathrm{Nv})$ and epithelial cells ( $\mathrm{Epi})$. The results are plotted at the time hydroxyurea was added. The appearance of newly differentiated nerve cells from Fig. 1 is shown for comparison (dotted line).

tween methanol extract treatment and hydroxyurea treatment increases. This increase is parallel to the appearance of differentiated nerve cells (Fig. 1) but occurs about $9 \mathrm{hr}$ earlier. Thus the time between the end of $\mathrm{S}$ phase and nerve cell differentiation is $9 \mathrm{hr}$. Since nerve precursors first become resistant to hydroxyurea $3 \mathrm{hr}$ after the onset of treatment with methanol extract, methanol extract must cause commitment $3 \mathrm{hr}$ prior to the end of $S$ phase.

Committed nerve precursors are blocked in the cell cycle. When hydra are treated with methanol extract but are not injured prior to treament, as in the previous experiment, a quite different result is obtained. Figure 3 shows the kinetics of nerve cell differentiation in hydra treated for varying periods of time with methanol extract containing $10^{-13} M$ head activator. At the end of the treatment pieces of tissue were explanted (equivalent to injury) and incubated for varying periods of time before scoring nerve cells. The results indicate no change in the Nv/Epi ratio during treatment with methanol extract. However, following explantation there is a sharp increase in new nerve cells within $5 \mathrm{hr}$. The size of this increase is greater with longer periods of treatment up to a maximum of about $0.18 \mathrm{Nv} / \mathrm{Epi}$ (Figs. 3 and 4).
The results in Fig. 3 demonstrate several features of nerve cell differentiation in hydra. Each of these is discussed below.

(1) Nerve cells do not differentiate at a fixed time after the onset of treatment with methanol extract. For example, in Fig. 3B large numbers of new nerve cells have differentiated by $17 \mathrm{hr}$ after the beginning of treatment with methanol extract whereas in Fig. $3 \mathrm{C}$ no new nerve cells have appeared by this time. This indicates that nerve precursors are blocked at some point between the time of commitment in the $\mathrm{S}$ phase and terminal differentiation.

(2) The block to nerve differentiation is released by explantation of pieces of tissue (Figs. 3B, C) or simply injuring whole animals (Holstein et al., 1986). Longer periods of treatment with methanol extract increase the number of nerve precursors which are blocked and hence the size of the Nv/Epi increase following explantation (Figs. 3B, C). Untreated control animals also contain a
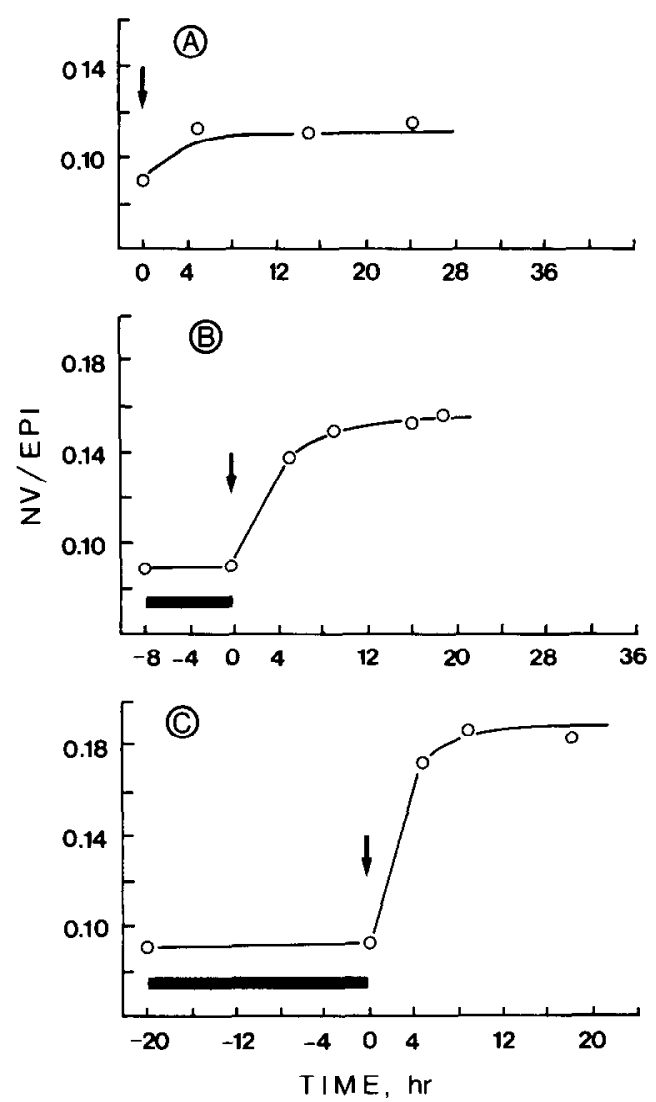

Fig. 3. Appearance of newly differentiated nerve cells as a function of the period of methanol extract treatment. Hydra were treated for 8 or $20 \mathrm{hr}$ (bars) with methanol extract containing $10^{-13} M$ head activator. At $0 \mathrm{hr}$ explants were prepared (arrow) and incubated in hydra medium. At the times shown, samples were macerated and scored for nerve cells (Nv) and epithelial cells (Epi). (A) untreted control aninals, (B) 8-hr methanol extract treatment, (C) 18-hr methanol extract treatment. 
small number of these precursors since the Nv/Epi ratio in such animals increased from 0.09 to 0.11 following explantation (Fig. 3A).

(3) The block to nerve cell differentiation occurs at a specific time in the differentiation pathway. Figure 4 shows the kinetics of nerve cell differentiation following explantation. In hydra treated for 12 or $20 \mathrm{hr}$ with methanol extract large numbers of committed precursors accumulated at the differentiation block. These cells differentiated synchronously within $5 \mathrm{hr}$ after explantation, indicating that the time between the block and nerve cell differentiation is less than $5 \mathrm{hr}$. A small number of nerve cells also differentiated in untreated control animals indicating that normal animals have small numbers of committed nerve precursors. In animals treated for $4 \mathrm{hr}$ with methanol extract, there was no increase in nerve cells over control levels until 6 to 12 $\mathrm{hr}$ after explantation. Thus, nerve cells differentiating in this interval are the products of nerve cell commitment induced by the 4-hr treatment with methanol extract. A similar increase in differentiated nerves also occurred from 6 to $12 \mathrm{hr}$ in the other treated samples and is presumably due to commitment events which occurred in the final $4 \mathrm{hr}$ of these treatments.

Localization of the block in the cell cycle. The results above demonstrate that methanol extract causes nerve cell commitment in S phase and that committed cells are blocked from completing differentiation at a later stage in the cell cycle. Since differentiated nerve cells have a postmitotic (G1) nuclear DNA content (David and Gierer, 1974), this block to differentiation could occur either before or after mitosis. If the block occurs before mitosis, then a wave of mitoses is expected to occur after explantation; if the block occurs after mitosis, then an increased number of $\mathrm{G} 1$ precursor cells should accumulate in animals treated with methanol extract.

In order to test these alternatives we analyzed the mitotic index of interstitial cells after explantation and the nuclear DNA content of putative nerve precursors. Figure 5 indicates that the mitotic index of interstitial cells decreases from $7.5 \%$ at the end of treatment with methanol extract to $3.6 \%$ by $12 \mathrm{hr}$ after explantation. Although the level of mitoses is slightly higher than in untreated animals, there is no evidence of a wave of interstitial cell mitoses in the $5 \mathrm{hr}$ after head activator treatment. Hence it appears unlikely that nerve precursors are blocked in G2.

If there is no G2 block, then there should be a subpopulation of interstitial cells which is blocked in G1. Because interstitial cells in G1 are normally rare (Campbell and David, 1974), such a subpopulation might be distinguishable from the rest of the interstitial cell population by its morphology as well as its nuclear DNA content. A likely candidate for nerve precursors is a population of small interstitial cells recently identified by Heimfeld and Bode (1984a). These cells occur as single cells (1s) or as nests of two cells (2s). They are about 6$10 \mu \mathrm{m}$ in diameter and have a large nucleus surrounded by relatively little cytoplasm (Fig. $6 \mathrm{~B}$ ). In contrast to large interstitial cells (Fig. 6A), the nucleus does not have a prominent nucleolus, but several small nucleoli which give the nucleus a mottled appearance.

Figure 5 shows the occurrence of this cell type during the first $5 \mathrm{hr}$ after explantation of tissue treated with

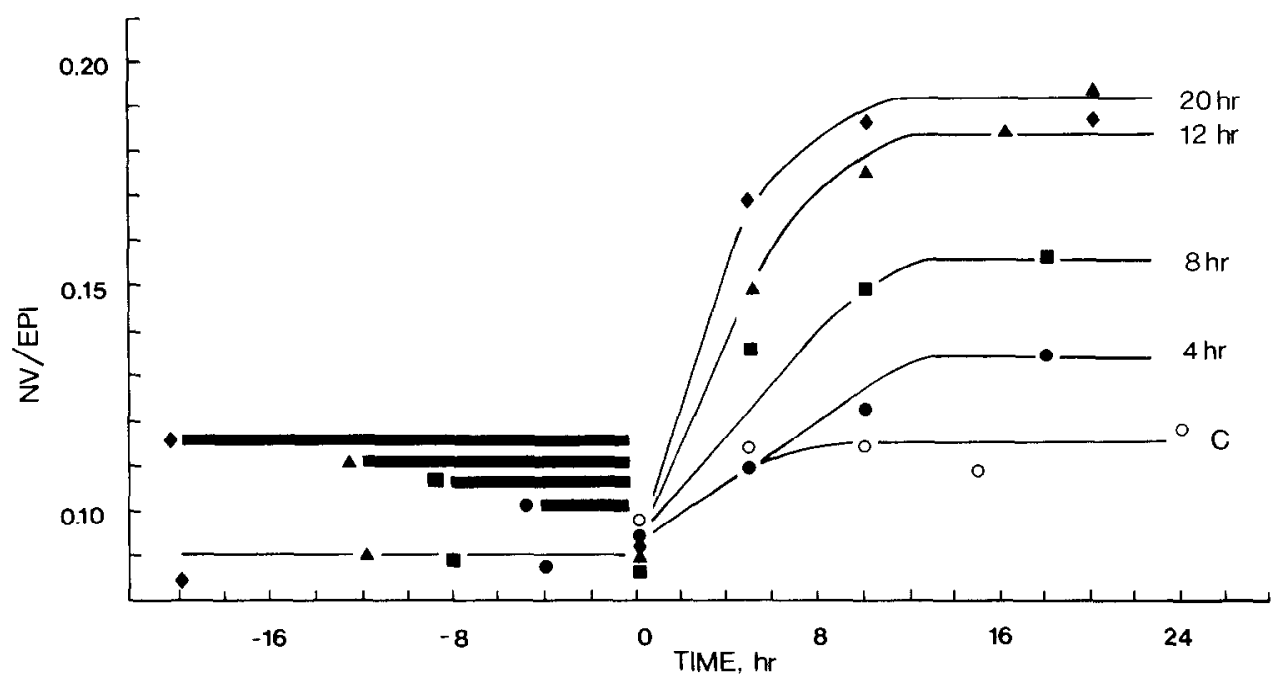

FIG. 4. Differentiation of committed nerve cell precursors in explants. Hydra were treated for varying periods with methanol extract containing $10^{-13} M$ head activator (bars). At $0 \mathrm{hr}$ explants were prepared and incubated in hydra medium. At the times shown samples were macerated and scored for nerve cells (Nv) and epithelial cells (Epi). Filled symbols indicate different periods of treatment with methanol extract $(4,8,12,20 \mathrm{hr})$; open circles indicate untreated control animals $(\mathrm{C})$. 

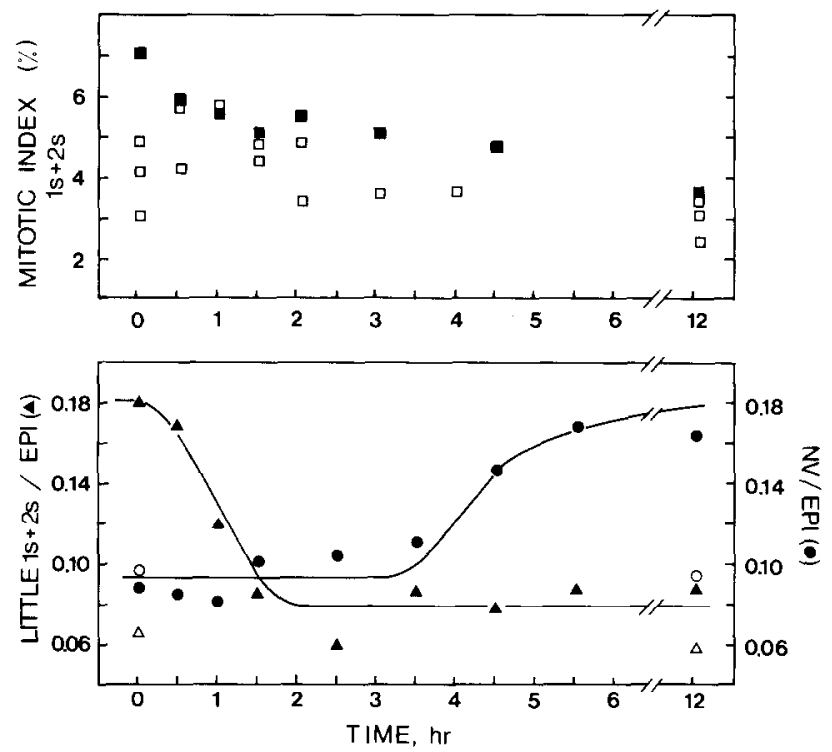

FIG. 5. Mitotic index of interstitial cells and the kinetics of precursor (small $1 s+2 s$ ) and nerve cell differentiation in explants of methanol extract treated hydra. Hydra were treated for $20 \mathrm{hr}$ with methanol extract containing $10^{-13} M$ head activator. At $0 \mathrm{hr}$ explants were prepared and incubated in hydra medium. Samples were macerated at the times shown and scored for mitotic cells $(\square, \square)$, small is $+2 \mathrm{~s}(\triangle$, $\Delta)$, nerve cells $(\mathrm{Nv})(\mathrm{O}, \bullet)$ and epithelial cells (Epi). Closed symbols: treated hydra; open symbols: untreated control hydra. Each point represents an independent experiment.

methanol extract. At the time of explantation there were approximately two times as many small interstitial cells in treated tissue as in untreated control animals. Within the first $2 \mathrm{hr}$ after explantation the number of these small interstitial cells decreased to control levels. If these cells are nerve precursors then the decrease in their numbers should be equal to the increase in nerve cells following explantation. Figure 5 shows that this is true. The ratio of Nv/Epi increased from 0.09 to 0.18 while the ratio of small $1 \mathrm{~s}+2 \mathrm{~s} /$ Epi decreased from 0.18 to 0.08 during the first $5 \mathrm{hr}$ after explantation.

To determine the cell cycle position of these cells, we measured the nuclear DNA content of interstitial cells after $22 \mathrm{hr}$ of treatment with methanol extract. In untreated control animals most interstitial cells (i.e., large and small $1 \mathrm{~s}$ and $2 \mathrm{~s}$ ) have nuclear DNA contents corresponding to $\mathrm{S}$ and $\mathrm{G} 2$ phase (Fig. 7A). However, in animals treated with methanol extract a subpoulation of cells with G1 nuclear DNA content appears in the distribution (Fig. 7B). Furthermore, the nuclear DNA distribution of the putative nerve precursors (small interstitial cells with typical nuclear morphology; Fig. 6B) shows that the majority of this population is G1 cells while only a small fraction seems to be in the S or G2 phase (Fig. 7C). Thus, treatment with methanol extract induces formation of a subpopulation of interstitial cells with a distinct nuclear morphology and G1 nuclear DNA content; following explantation these cells differentiate into nerve cells in 4-5 hr (Fig. 5). Hence, we conclude that the block to nerve cell differentiation in hydra treated with methanol extract occurs after mitosis in G1 phase of the precursor cells. Higure 5 also shows that the explantation (=injury) stimulus acts without delay since the small interstitial cell precursors to nerve cells begin to decline in number within 30 min of explantation.

Committed nerve cells are unstable. The results in Figs. 3 and 4 demonstrate qualitatively that longer treatment with methanol extract induces differentiation of larger
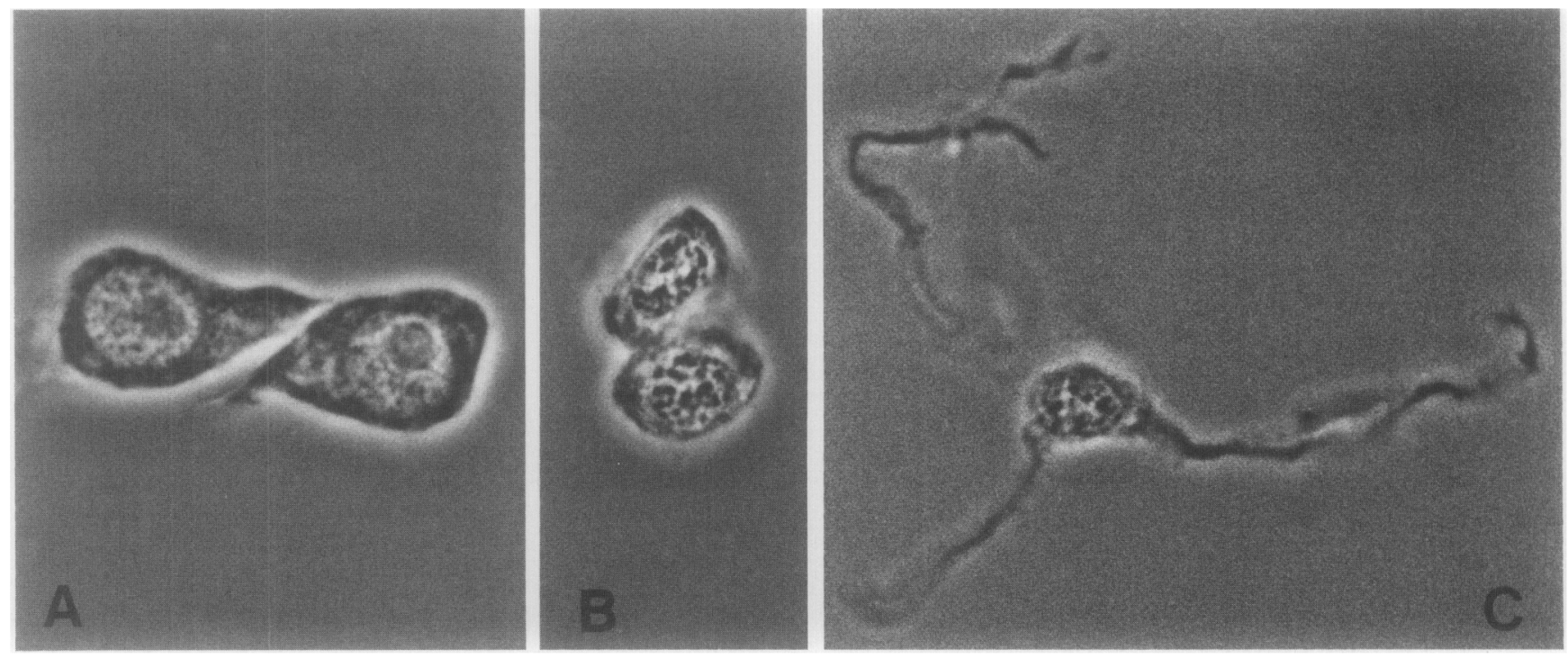

Fig. 6. Two classes of interstitial cells, (A) two large interstitial cells and (B) two small interstitial cells (nerve cell precursors), and (C) differentiated nerve cell from the gastric region. All micrographs are from macerated cell preparations. Phase contrast, $\times 1660$. 

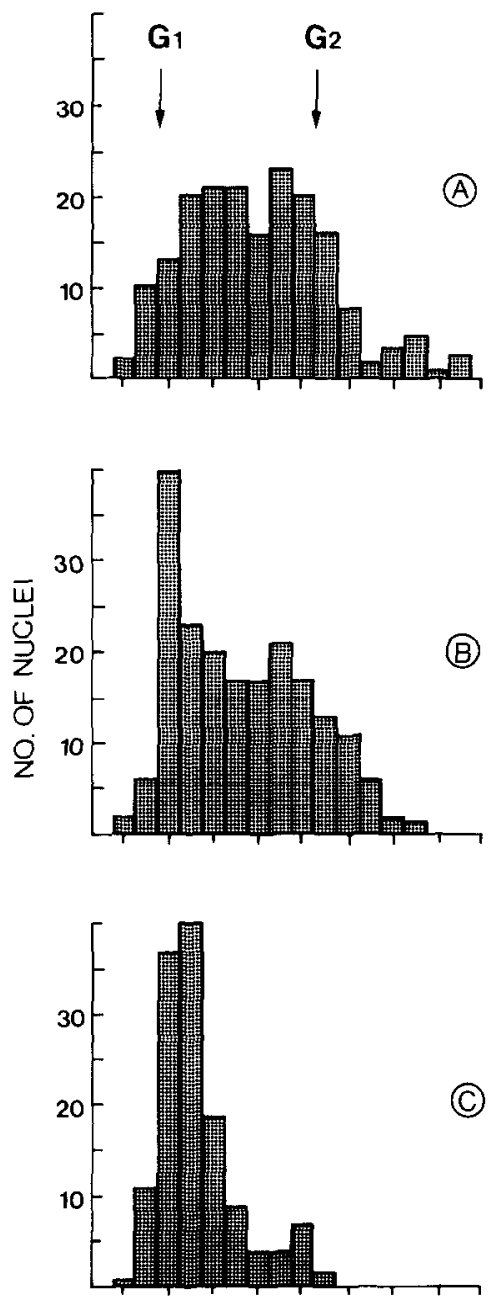

FLUORESCENCE

FIG. 7. Nuclear DNA content of interstitial cells determined by microfluorometry. (A) Total interstitial cells $(1 s+2 s)$ in untreated control hydra, (B) total interstitial cells $(1 \mathrm{~s}+2 \mathrm{~s})$ in hydra treated for $20 \mathrm{hr}$ with methanol extract containing $10^{-13} M$ head activator, (C) small interstitial cells $(1 s+2 s)$ identified by their nuclear morphology (see Fig. $6 \mathrm{~B}$ ) in hydra treated for $20 \mathrm{hr}$ with methanol extract. Abscissa: relative DNA content in arbitrary fluorescence units. Nuclei of nerve cells (G1 DNA content; David and Giercr, 1974) were used as a reference standard to determine the positions of G1 and G2.

numbers of new nerve cells following explantation of the treated tissue. However, when this effect is examined quantitatively with a larger set of data (Fig. 8), it becomes apparent that the increase in new nerve cells reaches a maximum after about $12 \mathrm{hr}$ of treatment. This maximum is not due to exhaustion of head activator in the methanol extract since addition of fresh extract after $12 \mathrm{hr}$ does not lead to a further increase in nerve cell differentiation (data not shown). In seeking to explain this rather puzzling observation we investigated the stability of committed nerve precursors.

Hydra were treated for $18 \mathrm{hr}$ with methanol extract to induce committed nerve precursors and then incu- bated for varying periods of time in hydra medium. Differentiation of the committed precursors was then induced by injury (rather than explantation) so that all the cells in the animal could be analyzed. Furthermore we labeled committed precursors with a pulse of $\left[{ }^{3} \mathrm{H}\right]$ thymidine $12 \mathrm{hr}$ after the onset of head activator treatment to provide a positive (radioactive) marker for differentiation.

The results of four such experiments are summarized in Fig. 9. In animals injured immediately after treatment with methanol extract and then incubated for $18 \mathrm{hr}$, the ratio of labeled nerve cells to epithelial cells $\left(\mathrm{Nv}^{*} / \mathrm{Epi}\right)$ was approximately 0.065 compared to a level of $0.1 \mathrm{Nv}^{*}$ / Epi in untreated control animals. This increase of about $0.055 \mathrm{Nv}^{*} / \mathrm{Epi}$ is about $60 \%$ of the total increase in new nerve cells (Fig. 8), indicating that only a portion of the committed nerve precursors is labeled by this protocol. Incubation of treated animals in hydra medium for a period of 12-36 hr prior to injury caused a striking reduction in the number labeled nerve cells which differentiated (Fig. 9). About one-half the labeled precursors failed to differentiate after a $12-\mathrm{hr}$ incubation in hydra medium and essentially none differentiated after $36 \mathrm{hr}$. This strongly suggests that the committed state is unstable and provides an explanation for the observed maximum level of committed nerve precursors in Fig. 8.

\section{DISCUSSION}

The results presented here are summarized schematically in Fig. 10. Treatment with methanol extract causes commitment of interstitial stem cells to nerve cell dif-

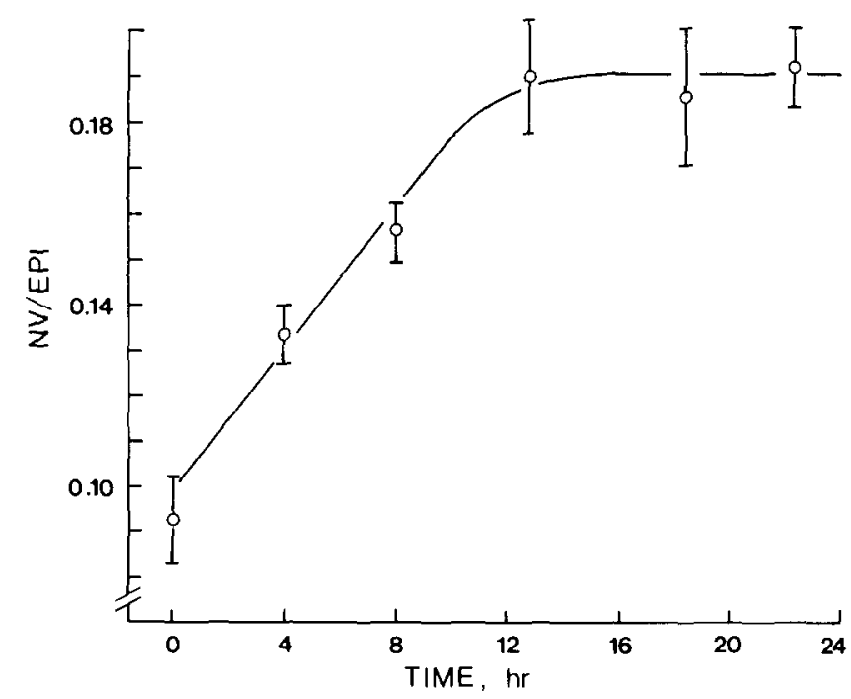

FIG. 8. Inerease in nerve cell differentiation as a function of duration of head activator treatment. Hydra were treated with methanol extract containing $10^{-13} M$ head activator for the times shown. After treatment explants were prepared, incubated for $18 \mathrm{hr}$ in hydra medium, macerated, and scored for nerve cells (Nv) and epithelial cells (Epi). The points are the averages $( \pm S D)$ of three experiments. 


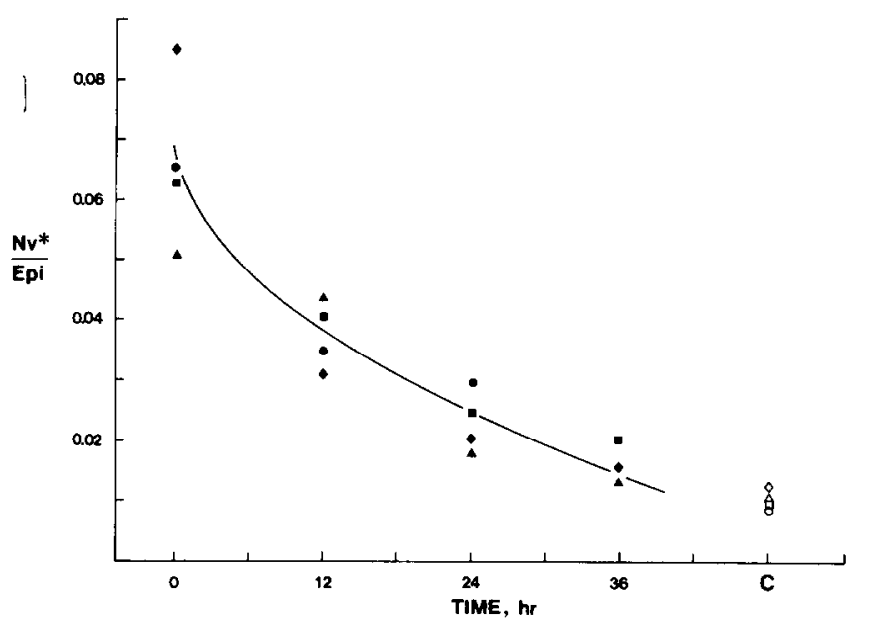

FIG. 9. Stability of committed nerve precursors. Hydra were treated with methanol extract containing $10^{-13} M$ head activator for $18 \mathrm{hr}$ (at $12 \mathrm{hr}$ animals were labeled with $\left[{ }^{3} \mathrm{H}\right]$ thymidine) and then incubated in hydra medium for the times shown. Thereafter animals were injured and incubated for an additional $18 \mathrm{hr}$ in hydra medium, macerated, autoradiographed, and scored for labeled nerve cells ( $\left.\mathrm{Nv}^{*}\right)$ and epithelial cells (Epi). Different symbols indicate independent experiments. Filled symbols: methanol extract-treated hydra. Open symbols: untreated control hydra which were labeled, incubated in hydra medium for $36 \mathrm{hr}$, injured, and incubated for $18 \mathrm{hr}$.

ferentiation. Commitment occurs in $\mathrm{S}$ phase $12 \mathrm{hr}$ before terminal nerve differentiation (Fig. 1). Committed precursors pass from $\mathrm{S}$ into $\mathrm{G} 2$ about $9 \mathrm{hr}$ before nerve differentiation (Fig. 2), divide, and then arrest in G1 (Fig. 7C). From the G1 arrest to differentiated nerve cell requires another $4 \mathrm{hr}$ (Figs. 4 and 5). Thus, nerve cell differentiation in hydra is regulated at two different points in the precursor cell cycle.

The observation that methanol extract causes commitment in $\mathbf{S}$ phase is in good agreement with previous results which showed that nerve cell commitment induced by head regeneration occurs in S phase (Venugopal and David, 1981b; Yaross et al., 1982) and that head activator is released during head regeneration (Schaller, 1976c). Earlier experiments of Schaller (1976b) also demonstrated that head activator stimulated nerve cell commitment in early $\mathrm{S}$ phase. Thus it seems likely that head activator is the in vivo signal controlling the pattern of nerve cell differentiation in hydra.

Properties of committed nerve cell precursors. Our results indicate the existence of a population of committed nerve precursors in hydra. Differentiation of these cells is controlled by a block in G1 phase prior to neurite outgrowth. Following prolonged treatment with head activator sufficient numbers of these cells accumulate to be recognized as a subpopulation of interstitial cells. They can be distinguished from the rest of the interstitial cell population by their small size and characteristic nuclear morphology (Fig. 6B) and by their nuclear DNA content (Fig. 7C). This population of cells increases dur- ing head activator treatment and then decreases following release of the G1 block to an extent which agrees quantitatively with the increase in newly differentiated nerve cells (Fig. 5). Hence it appears likely that these cells are the immediate precursors to differentiated nerve cells. An interesting and unexpected feature of these cells is that they are unstable, decaying with a half-life of about $12 \mathrm{hr}$ if not induced to differentiate (Fig. 9).

It is important to note that not all little interstitial cells with the morphological features of the nerve precursors described above are in fact nerve precursors. From the results in Fig. 5 it is clear that hydra contain a basal level of these cells which do not differentiate as nerve cells. It seems likely that this population consists of interstitial cells in the normal mitotic cycle. Hydra contain about $0.4(1 \mathrm{~s}+2 \mathrm{~s}) / \mathrm{Epi}$. These cells are actively proliferating and hence a fraction of them are mitotic daughter cells. Such cells would be morphologically similar to the G1 nerve precursors but would contain more nuclear DNA since $\mathrm{S}$ phase begins immediately after mitosis in hydra cells. The results in Fig. 7C suggest that such cells are indeed present in the population of small interstitial cells. Assuming cells remain in this state for the first $3 \mathrm{hr}$ after mitosis, then about $20 \%$ of the $1 \mathrm{~s}+2 \mathrm{~s}$ or 0.08 cells/Epi should be in this state (assuming a stem cell cycle of $27 \mathrm{hr}$ and correcting for the age distribution of the proliferating cells). This estimate is in rough agreement with the observed basal level of these cells (Fig. 5).

A similar subpopulation of interstitial cells has recently been identified by Heimfeld and Bode (1984a) in grafting experiments between normal tissue and epithelial tissue. In these grafts, the interstitial cells migrated into the interstitial cell free (epithelial) tissue and differentiated into nerve cells. (It seems likely that differentiation occurred in these experiments due to the cuts made in the tissue during the grafting procedure.) Because this population could be labeled with

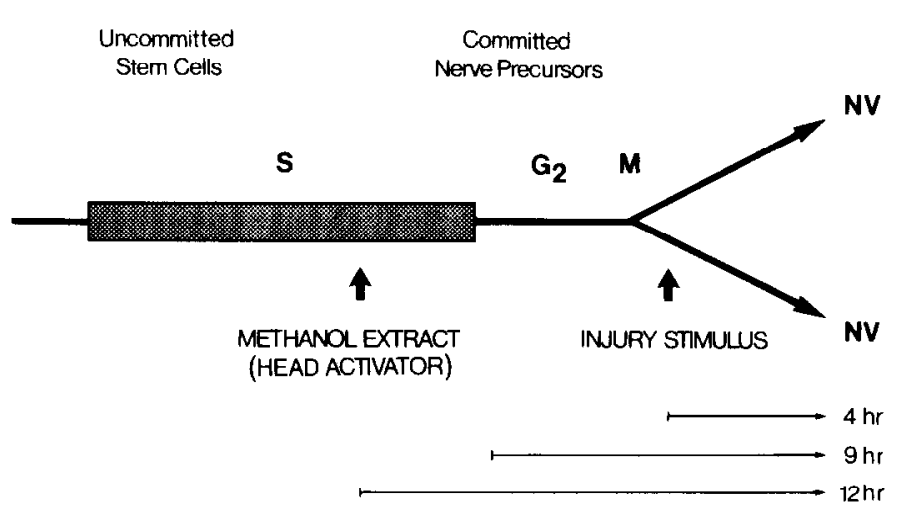

FIG. 10. Schematic representation of events in nerve cell differentiation pathway. 
$\left[{ }^{3} \mathrm{H}\right]$ thymidine, Heimfeld and Bode suggested that such committed cells underwent another round of cell division prior to differentiation in contrast to our observations. However, a more likely explanation for their results is that, as in our case (Fig. 5), some of these migrating small interstitial cells are proliferating stem cells and not committed nerve precursors.

It is interesting to note that G1 blocks to differentiation occur in a number of other systems, e.g., neural crest cells (Payette et al. 1984), myoblasts (Riddle and Pardee, 1980; Konieczny et al., 1982), yeast cells (Nurse and Bissett, 1981; Moore, 1984).

The postulated "G2 block" to nerve differentiation. Our observation that nerve precursors are blocked in G1 was surprising since several earlier reports had suggested the existence of a population of nerve cell precursors in G2. In particular, Schaller (1976b) showed that head activator treatment caused a small increase in nerve cell differentiation within $6 \mathrm{hr}$. Since head activator also stimulated mitosis, she suggested that head activator stimulated nerve cell precursors "blocked in G2" to divide and differentiate. These results appear to be quite different from ours. In comparing both results, however, it is important to note a difference in the experimental protocols. Schaller used young buds for her experiments. In such animals the "bud initiation effect" persists and there is no G1 block to nerve differentiation (Holstein et al., 1986). In our experiments, older animals were used which exhibit a G1 block to nerve differentiation. Hence, head activator-induced shortening of G2 is expected to stimulate nerve differentiation in Schaller's animals whereas in our animals the same G2 shortening leads to an accumulation of G1 nerve precursors but no nerve differentiation. Schaller's results are best interpreted as a transient perturbation of the cell cycle rather than a specific block to nerve differentiation.

Berking (1980) also suggested that nerve cell precursors "blocked in G2" are present in the body column of hydra. These cells accumulate in bud anlagen and differentiate as nerves $5 \mathrm{hr}$ after the onset of bud evagination. Berking provided no experimental evidence that the precursors were in G2. Since the kinetics of nerve differentiation are similar in buds and in animals containing G1 nerve precursors (Fig. 5), it appears likely that nerve precursors in buds are also blocked in G1 and that the injury stimulus mimics the signal initiating bud evagination.

Sorting out versus local cell commitment. The existence of two mechanisms controlling nerve cell differentiation at different points in the pathway (Fig. 10) provides an explanation for conflicting reports concerning the mechanism by which the pattern of nerve cell differentiation is achieved in vivo. Nerve cell differentiation is extensive in head and foot regions and less frequent throughout the rest of the body column (David and
Gierer, 1974). Several investigators have provided evidence for position-dependent signals causing nerve cell commitment in head tissue (Venugopal and David, 1981a; Heimfeld and Bode, 1980). Other investigators have observed extensive migration of nerve cell precursors (Berking, 1980; Heimfeld and Bode, 1984a,b) and have proposed that the pattern of nerve differentiation is due to a cell sorting mechanism in which committed nerve precursors migrate from the gastric region to head and foot regions before differentiating.

The present results suggest mechanisms for both hypotheses. A spatial pattern of head activator could cause the observed spatial pattern of nerve cell commitment. The G1 block to nerve differentiation creates a population of committed precursors which are migratory. Differentiation of these cells could be controlled by local signals which release the G1 block, e.g., the signal stimulating bud evagination. The range over which such cells could migrate would be limited by the lifetime of the committed cells.

The authors thank Th. Bosch, H. K. MacWilliams, and C. Weijer for critically reading the manuscript. This research was supported by the Deutsche Forschungsgemeinschaft (Da 163-1-1).

\section{REFERENCES}

BERKING, S. (1980). Commitment of stem cells to nerve cell precursors in preparatory bud development in Hydra. J. Embryol. Exp. Morphol 60, 373-387.

Bode, H. R., Berking, S., David, C. N., Gierer, A., Schaller, H., and TREnkner, E. (1973). Quantitative analysis of cell types during growth and morphogenesis in Hydra. Wilhelm Roux's Arch. Eutwicklungsmech. Organismen 171, 269-285.

BoDE, H. R., and DAvID, C. N. (1978). Regulation of a multipotent stem cell, the insterstitial cell of hydra. Prog. Biophys. Mol. Biol. 33, 189206.

Bodenmuller, H. and ZachmanN, B. (1983). A radioimmunoassay for the Hydra head activator. FEBS Lett. 159, 237-240.

CampBell, R. D., and DAvid, C. N. (1974). Cell cycle kinetics and development in Hydra attenuata. II. Interstitial cells. J. Cell Sci. 16, 344-358.

Coleman, A. W.. and Maguire, M. J. (1982). A microspectrofluorometric analysis of nuclear and chloroplast DNA in Volvox. Dev. Biol. 94, $441-450$.

DAvID, C. N. (1973). A quantitative method for maceration of Hydra tissue. Wilhelm Roux's Arch. 171, 259-268.

DAvid, C. N., and CAMPBELL, R. (1972). Cell cycle kinetics and development of Hydra attenuata. I. Epithelial cells. J. Cell Sci. 11, 557568.

DAVID, C. N., and GIERER, A. (1974). Cell cycle kinetics and development of Hydra attenuata. III. Nerve and nematocyte differentiation. $J$. Cell Sci. 16, 359-375.

DAVID, C. N., and MurPHY, S. (1977). Characterization of interstitial stem cells in Hydra by cloning. Dev. Biol. 58, 372-383.

Fujisawa, T., and David, C. N. (1982). Commitment during stenotele differentiation in $H y d r a$ is localized near S/G2 boundary in the terminal cell cycle. Dev. Biol. 93, 243-255.

HEImfELD, S., and BoDE, H. R. (1981). Regulation of interstitial cell differentiation in Hydra attenuata. II. Positional pattern of nerve cell commitment is dependent on local nerve cell density. J. Cell Sci. 52, 85-98.

Heimfeld, S., and BoDE, H. K. (1984a). Interstitial cell migration in 
Hydra attenuata. I. Quantitative description of cell movements. Dev. Biol. 105, 1-9.

HeImFELD, S., and BODE, H. K. (1984b). Interstitial cell migration in Hydra attenuata. II. Selective migration of nerve cell precursors as the basis for position dependent nerve cell differentiation. Dev. Biol 105, 10-17.

Holstein, TH., Schaller, H. C., and David, C. N. (1986). Nerve cell differentiation in hydra requires two signals. Dev. Biol. 115, 9-17.

KONIECZNY, S. F., MCKAY, J., and Coleman, J. R. (1982). Isolation and characterization of terminally differentiated chicken and rat skeletal muscle myoblasts. Dev. Biol. 91, 11-26.

LEEMANN, U., and RUCH, F. (1982). Cytofluorometric determination of DNA base content in plant nuclei and chromosomes by the fluorochrome DAPI and Chromomycin A3. Exp. Cell Res. 140, 275-282.

MOORE, S. A. (1984). Synchronous cell growth occurs upon synchronizing the two regulatory steps of the Saccharomyces cerevisiae cell cycle. Exp. Cell Res. 151, 542-556.

NURSE, P., and BISSETT, Y. (1981). Gene required in G1 for commitment to cell cycle and in G2 for control of mitosis in fission yeast. Nature (London) 292, 558-560.

Park, H., Orthmeyer, A., and Blankenbaker, D. (1970). Cell division during regeneration in Hydra. Nature (London) 277, 617-619.

PAyette, R. F., Bennett, G. S., and Gershon, M. D. (1984). Neurofilament expression in vagal neural crest-derived precursors of enteric neurons. Dev. Biol. 105, 273-287.
RIDdle, V. G. H., and PARdeE, A. B. (1980). Quiescent cells but not cycling cells exhibit enhanced actin synthesis before they synthesize DNA. J. Cell. Physiol. 103, 11-15.

SCHALLER, H. C. (1976a). Action of head activator as a growth hormone in Hydra. Cell Diff. 5, 1-11.

SCHALLER, H. C. (1976b). Action of head activator on the determination of interstitial cells in Hydra. Cell Diff. 5, 13-20.

SCHALLER, H. C. (1976c). Head regeneration in Hydra is initiated release of head activator and inhibitor. Wilhelm Roux's Arch. 180, 287-295.

VENUGOPAL, G., and DAVID, C. N. (1981a). Nerve commitment in Hydru. I. Role of morphogenetic signals. Dev. Biol. 83, 353-360.

Venugopal, G., and DAVID, C. N. (1981b). Nerve commitment in Hydra. II. Localization of commitment in S phase. Dev. Biol. 83, 361-365.

Venugopal, G., and David, C. N. (1981c). Spatial pattern of nerve differentiation in Hydra is due to a pattern of nerve commitment. Dev. Biol. 83, 366-369.

YAROSS, M., BACA, B. A., CHOW, M. H., and BodE, II. R. (1982). Commitment of hydra interstitial cells to nerve cell differentiation occurs by late S-phase. Dev. Biol 89, 425-436.

YAROSS, M. S., and BODE, H. R. (1978a). Regulation of interstitial cell differentiation in Hydra attenuata. III. Effects of i-cell and nerve cell densities. J. Cell Sci. 34, 1-26.

YAROSS, M. S., and BODE, H. R. (1978b). Regulation of interstitial cell differentiation in Hydra attenuata. IV. Nerve cell commitment in head regeneration is position dependent. J. Cell Sci. 34, 27-38. 